\title{
Productivity Analysis Of Filling Machine With The Objective Matrix (OMAX) Method
}

\author{
Katrin Agnes Eyrani Sinaga ${ }^{1 *}, K_{\text {Kevin }}$ Lie $^{1}$, Nico Williams ${ }^{1}$, Theresia Sunarni ${ }^{1}$ \\ ${ }^{1}$ Industrial Engineering Study Program, Musi Charitas Catholic University, Palembang \\ *Email: katrin.sinaga22@gmail.com
}

\begin{abstract}
A Factory is a manufacturing industry that produces tea drinks in cups. A Factory is also inseparable from problems related to machine/equipment productivity. Based on the results of observations made at A Factory part of the production line that there is often a sudden stop of the production process. The discontinuation will affect the quality of the product expected and the production targets to be achieved. The problem was discussed in this research is how much the productivity level of the filling production department is, how much the production effectiveness, effective working hours, the number of defective products, and machine downtime criteria. The productivity measurement method used is the Objective Matrix (OMAX) method, so the steps of this study refers to OMAX steps, which is the criteria determination/productivity ratio of the production line, the calculation of the productivity ratio value, the calculation of the initial standard score (score 3), The determination of the goal (score 10) and the lowest score (score 0 ), the determination of weight, the calculation of value/criteria value, the determination of productivity value for each period, determination of index percentage. With the OMAX method, it can be seen that in period 11 (compared to period 10) there was an increase in productivity, this can be seen because the IP value (Index of Performance) which is positive (+) is 27.79 and there is an increase in the value of the calculation at the time of measurement (current) from 383.36 to 300 . This increase was due to an increase in the value of all criteria.
\end{abstract}

\section{Keyword: Filling Machine, Index of Performance (IP), Manufacture Industry, Objective Matrix (OMAX)}

\begin{abstract}
Abstrak
Sebuah perusahaan yang merupakan salah satu industri manufaktur yang memproduksi minuman teh dalam cup. Perusahaan juga tidak terlepas dari masalah yang berkaitan dengan produktivitas mesin/peralatan. Bedasarkan hasil pengamatan yang dilakukan di perusahaan bagian lini produksi bahwa sering terjadi pemberhentian proses produksi secara tiba - tiba. Pemberhentian tersebut akan berpengaruh pada kualitas dari produk yang diharapkan dan target produksi yang akan dicapai. Penelitian ini bertujuan untuk mengevaluasi penurunan produktivitas dari mesin filling yaitu dengan mengukur nilai produktivitas yang didasarkan pada 4 kriteria yaitu kriteria efektifitas hasil produksi, Jam kerja efektif, kriteria jumlah produk cacat, dan kriteria downtime mesin. Metode yang digunakan adalah Objective Matrix (OMAX), dengan langkah penentuan kriteria, perhitungan rasio, perhitungan interpolasi nilai matriks, penetapan sasaran, penentuan bobot dan pembentukan matriks. Dengan Metode OMAX dapat diketahui pada periode 11 (dibandingkan dengan periode 10) terjadi kenaikan produktivitas, hal itu dapat terlihat karena nilai IP (indeks produktivitas) yang bernilai positif (+) yaitu sebesar 27,79 dan terjadi kenaikan dinilai perhitungan pada saat pengukuran (current) dari 383,36 menjadi 300. Peningkatan ini disebabkan karena terjadinya peningkatan nilai dari seluruh kriteria.
\end{abstract}

Kata kunci: Mesin filling, Indeks Produktivitas (IP), Industri Manufaktur, Objective Matrix (OMAX)

\section{PENDAHULUAN}


Dewasa ini, dunia industri manufaktur berkembang sangat pesat. Setiap perusahaan harus selalu melakukan peningkatan secara berkelanjutan (continous improvement) disetiap departemen agar mampu bersaing dalam era globalisasi, khususnya di lini produksi. Lini produksi merupakan lini yang sangat vital dalam sebuah perusahaan. Dalam lini produksi, terdapat berbagai hal yang perlu ditingkatkan produktivitasnya, termasuk peralatan dan mesin yang mendukung proses produksi.

Semakin pesatnya perkembangan suatu teknologi dan perubahan zaman membuat persaingan antar perusahaan sejenis menjadi semakin ketat, perlu adanya strategi yang mampu meningkatkan produktivitas agar perusahaan mampu mengelola sistem produksi dengan baik, meningkatkan efisiensi sumber daya yang digunakan, meningkatkan kualitas produk dan memenuhi target permintaan konsumen (Avianda et al., 2014).

Pencapaian perusahaan dapat dilihat dari produktivitas yang dihasilkan. Karena hal ini yang menjadikan perusahaan semakin berkembang. Oleh karena itu, diperlukan suatu pengukuran produktivitas agar peningkatan produktivitas dapat terkendali dan sesuai dengan target perusahaan. Pengukuran produktivitas ini mempunyai banyak manfaat yang akan menjadi landasan dalam membuat kebijakan perbaikan produktivitas secara keseluruhan. Banyak penelitian yang menggunakan indeks produktivitas sebagai capaian keberhasilan perusahaan sehingga dapat dilakukan evaluasi terhadap kendala yang dihadapi perusahaan dan mampu memberikan solusi untuk dapat meningkatkan produktivitasnya (Zanuar, 2014; Avianda et al., 2014; Pangaula et al., 2015). Sumanth (1984) menjelaskan bahwa produktivitas sebagai siklus produktivitas. Ada empat tahap dalam konsep siklus produktivitas,yaitu: pengukuran produktivitas, evaluasi produktivitas, perencanaan produktivitas, dan peningkatan produktivitas.

Perusahaan merupakan salah satu industri manufaktur yang memproduksi minuman teh dalam cup. Perusahaan juga tidak terlepas dari masalah yang berkaitan dengan produktivitas mesin/peralatan. Bedasarkan hasil pengamatan yang dilakukan perusahaan bagian lini produksi bahwa sering terjadi pemberhentian proses produksi secara tiba-tiba. Pemberhentian tersebut akan berpengaruh pada kualitas dari produk yang diharapkan. Dari data yang diperoleh, jumlah produk cacat yang dihasilkan melebihi dari batas standar yang ditetapkan perusahaan. Selain itu, juga akan menyebabkan kerugian dalam hal finansial bagi perusahaan.

\section{METODE PELAKSANAAN}

Metode penelitian adalah suatu cara yang digunakan untuk melakukan kegiatan ilmiah berupa penelitian secara terencana, sistematis, terarah dan bertujuan untuk mengumpulkan data yang relevan guna memecahkan suatu permasalahan. Metode penelitian secara operasional diartikan sebagai suatu cara yang dilakukan untuk mendapatkan data atau informasi maupun untuk membahas suatu persoalan yang dihadapi. Metode pengukuran produktivitas yang digunakan adalah metode Objective Matrix (OMAX). "Objective Matrix (OMAX) adalah suatu sistem pengukuran produktivitas parsial yang dikembangkan untuk memantau produktivitas di tiap bagian perusahaan dengan kriteria produktivitas yang sesuai dengan keberadaaan bagian tersebut. Metode OMAX relatif sederhana dan mudah dipahami, mudah dilaksanakan dan tak memerlukan keahlian khusus, atanya mudah diperoleh, dan lebih fleksibel, tergantung pada masalah yang dihadapi” (Rahmi et al., 2013).

Didalam metode ini langkah-langkah yang harus dilakukan yaitu menentukan kriteria, perhitungan rasio, perhitungan interpolasi nilai matriks, penetapan sasaran, penetapan bobot rasio, pembentukan matriks dengan model Omax. Setelah perhitungan dengan Omax maka akan didapatkan index perubahan produktivitas yang selajutnya dilakukan evaluasi produktivitas dan usulan rencana untuk masa yang akan datang" (Agustina \& Riana, 2011). 
Katrin, et al Productivity analysis of filling machine with the objective matrix (OMAX) method

Raden Farisz (2010) menegaskan," Perhitungan performance indicator terdiri dari tiga,

1. Current adalah hasil pengukuran produkivitas periode sekarang yang diperoleh dengan menjumlahkan value tiap kriteria produktivitas yang diukur.

2. Previous adalah hasil pengukuran produktivitas periode sebelumnya.

3. Index adalah indikasi perubahan produktivitas yang terjadi pada perusahaan."

\section{HASIL DAN PEMBAHASAN}

\section{Kriteria effektifitas hasil produksi}

Kriteria ini merupakan pengukuran produktivitas jumlah hasil produksi aktual (pcs) dengan standar output yang harus dicapai (pcs), kriteria ini dipilih untuk mengetahui perbandingan antara jumlah hasil produksi yang telah dihasilkan dengan target produksi yang telah ditetapkan. Rasio-rasio yang menyusun kriteria effektifitas produksi: $\frac{\text { Akual hasil produksi (Pcs) }}{\text { Standar hasil Produksi (PCS) }} \times 100 \%$

\section{Kriteria jam kerja efektif}

Kriteria ini merupakan pengukuran produktivitas jam kerja yang tersedia dengan jam mesin idle, kriteria ini dipilih untuk mengetahui perbandingan antara jam kerja yang tersedia dengan dengan jumlah jam mesin idle. Rasio - rasio yang menyusun kriteria jam kerja efektif:

$\frac{\text { Jam kerja tersedia }(j a m)}{\text { Jam kerja mesin }(j a m)} \times 100 \%$

\section{Kriteria Jumlah Produk Cacat}

Kriteria ini merupakan pengukuran produktivitas jumlah produk cacat yang dihasilkan dengan total hasil produksi. Kriteria ini dipilih untuk mengetahui perbandingan antara produk cacat dengan total hasil produksi. Rasio - rasio yang menyusun kriteria Jumlah produk cacat:

$\frac{\text { Aktual Jumlah produk cacat (Pcs) }}{\text { Jumlah total produksi (PcS) }} \times 100 \%$

\section{Kriteria Downtime Mesin}

Kriteria ini merupakan pengukuran Downtime mesin dengan jam kerja mesin. Kriteria ini dipilih untuk mengetahui perbandingan downtime dengan jam kerja mesin. Rasio - rasio yang menyusun kriteria Jumlah Downtime:

$\frac{\text { Aktual Downtime }(\mathrm{min})}{\text { Jam kerja mesin }(\mathrm{min})} \times 100 \%$

Nilai masing-masing kriteria produktifitas ditunjukkan pada Tabel 3.1.

\begin{tabular}{ccccc}
\hline \multirow{2}{*}{ Bulan } & $\begin{array}{c}\text { Produktivitas } \\
\text { Kriteria 1 }(\%)\end{array}$ & $\begin{array}{c}\text { Produktivitas } \\
\text { Kriteria 2 }(\%)\end{array}$ & $\begin{array}{c}\text { Produktivitas } \\
\text { Kriteria 3 }(\%)\end{array}$ & $\begin{array}{c}\text { Produktivitas } \\
\text { Kriteria 4 }(\%)\end{array}$ \\
\hline 1 & 94,62 & 92,83 & 1,57 & 7,73 \\
2 & 96,17 & 90,45 & 0,95 & 10,56 \\
3 & 89,19 & 93,21 & 1,24 & 7,28 \\
4 & 95,16 & 83,35 & 1,22 & 19,97 \\
5 & 87,53 & 91,08 & 1,15 & 9,80 \\
6 & 98,84 & 82,62 & 0,89 & 21,04 \\
7 & 94,76 & 86,24 & 0,44 & 15,95 \\
\hline
\end{tabular}


Katrin, et al Productivity analysis of filling machine with the objective matrix (OMAX) method

\begin{tabular}{ccccc}
\hline 8 & 85,09 & 86,44 & 0,88 & 15,68 \\
9 & 101,36 & 75,71 & 1,21 & 32,08 \\
10 & 94,10 & 85,27 & 0,90 & 17,27 \\
\hline
\end{tabular}

Tabel 3.1. Nilai Kriteria Produktifitas

\begin{tabular}{|c|c|c|c|c|c|c|}
\hline \multirow{2}{*}{ No } & \multirow{2}{*}{$\begin{array}{l}\text { Productivity } \\
\text { Criteria }\end{array}$} & \multirow{2}{*}{ Units } & \multicolumn{3}{|c|}{1 Jan - 30 Oktober 2020} & \multirow{2}{*}{$\begin{array}{c}\text { Measured } \\
\text { performance } \\
\text { on } \\
01-\mathrm{Nov}-20\end{array}$} \\
\hline & & & $\begin{array}{l}\text { The worst } \\
\text { performance }\end{array}$ & $\begin{array}{c}\text { Expected } \\
\text { performance }\end{array}$ & $\begin{array}{c}\text { Based } \\
\text { performance }\end{array}$ & \\
\hline 1 & $\begin{array}{l}\text { Rasio Efektifitas } \\
\text { hasil produksi }\end{array}$ & $\%$ & 85,09 & 100 & 98,3 & 95 \\
\hline 2 & $\begin{array}{l}\text { Rasio Jam kerja } \\
\text { efektif }\end{array}$ & $\%$ & 75,71 & 100 & 93,21 & 95 \\
\hline 3 & $\begin{array}{l}\text { Rasio Jumlah } \\
\text { Produk Cacat }\end{array}$ & $\%$ & 1,57 & 0,1 & 0,09 & 0,1 \\
\hline 4 & $\begin{array}{l}\text { Rasio Downtime } \\
\text { mesin }\end{array}$ & $\%$ & 32,08 & 10 & 7,28 & 8 \\
\hline
\end{tabular}

Tabel 3.2. Nilai Kriteria Terburuk, Terbaik, dan Yang Diharapkan

\begin{tabular}{|c|c|c|c|c|c|}
\hline & $\mathbf{A}$ & B & C & D & TOTAL \\
\hline $\bar{A}$ & & $\mathrm{~A}$ & $\mathrm{C}$ & $\mathrm{A}$ & 2 \\
\hline B & & & B & $\mathrm{D}$ & 1 \\
\hline $\bar{C}$ & & & & $\mathrm{C}$ & 1 \\
\hline D & & & & & 0 \\
\hline TOTAL & 0 & 0 & 1 & 1 & \\
\hline
\end{tabular}

Tabel 3.3. Matrik Pilihan Berpasangan

Menghitung hasil perbandingan pilihan-berpasangan secara horisontal dan vertikal, menjumlahkan skor untuk masing-masing alternatif dan mendapatkan hasil sebagai berikut:

Kriteria $\mathrm{A}=2$

Kriteria $\mathrm{C}=2$

Kriteria $\mathrm{B}=1$

Kriteria $\mathrm{D}=1$

Total $=6$

Bobot masing-masing kriteria :

Bobot A : $\frac{\text { Kriteria A }}{\text { Total }} \times 100 \%=\frac{2}{6} \times 100 \%=33,33 \%$

Bobot C : $\frac{\text { Kriteria C }}{\text { Total }} \times 100 \%=\frac{2}{6} \times 100 \%=33,33 \%$

Bobot B : $\frac{\text { Kriteria B }}{\text { Total }} \times 100 \%=\frac{1}{6} \times 100 \%=16,67 \%$

Bobot D : $\frac{\text { Kriteria D }}{\text { Total }} \times 100 \%=\frac{1}{6} \times 100 \%=16,67 \%$ 


\section{Pengukuran Produktivitas}

Dalam pengukuran produktivitas dengan model Objective Matrix (OMAX) terdapat badan matrix yang dibagi dalam sepuluh tingkatan yang mempunyai tingkatan nilai. Sedangkan performance indicator terdiri dari: current (jumlah nilai saat pengukuran), previous (jumlah pengukuran priode sebelumnya), dan indeks produktivitas (IP).

Berdasarkan Riggs (1987), skala performansi dibagi ke dalam tiga level yang menjadi titik acuan. Level 0 ditentukan berdasarkan nilai rasio terendah dari perhitungan rasio produktivitas. Level 3 ditentukan dari perhitungan rata-rata nilai rasio pada masingmasing kriteria produktivitas yang kemudian disebut performansi standar. Level 10 ditentukan berdasarkan target yang ingin dicapai pada tahun yang akan datang. Hasil penentuan bobot diletakkan pada baris weight (\%) untuk setiap kriteria produktivitas. Penentuan skala performansi dari setiap level tersebut dapat dilihat pada Tabel 3.4 di bawah ini.

Perbandingan antara periode yang diukur dengan periode sebelumnya adalah untuk mengetahui apakah terjadi kenaikan atau penurunan produktivitas. Setelah dilakukan perhitungan maka didapatkan hasil pengukuran kinerja dalam Tabel 4 (contoh pada periode 11). Dari hasil pengukuran didapatkan hasil sebagai berikut: kriteria 1 terletak pada level ke-2; kriteria 2 terletak pada level ke-5; kriteria 3 terletak pada level ke-3, kriteria 4 terletak pada level ke-3.

Contoh perhitungan nilai aktual pada setiap score (level) dengan cara interpolasi:

\begin{tabular}{cc}
\hline Score & Nilai aktual \\
\hline 10 & 100 \\
3 & 98,3 \\
\hline
\end{tabular}

Rumus Interpolasi: $(\mathrm{x}=$ score, $\mathrm{y}=$ nilai aktual $)$

$\mathrm{P}(4) \quad=\mathrm{Yo}+\frac{Y i-Y 0}{X 1-X 0}(\mathrm{X}-\mathrm{X} 0)=98,3+\frac{(100-98,3)}{10-3}(4-3)=98,54$

Dengan cara yang sama, hitung nilai aktual pada score 5-9, sedangkan nilai pada score 1-2 didapat dari data dengan nilai buruk yang pernah terjadi sebelumnya.

Untuk menentukan Value, digunakan rumus :

Value $=$ Score $x$ Weight

Productivity Indicator $=$ a sum of all values

$$
\begin{aligned}
& =66,66+83,35+99,99+133,36 \\
& =383,36
\end{aligned}
$$

Untuk menentukan Index of Performance digunakan rumus :

$=($ Productivity Indicator - Based Performance $) /$ Based Performance $) \times 100 \%$

$=((383,36-300) / 300) \times 100 \%$

$=27,79 \%$ 
Katrin, et al Productivity analysis of filling machine with the objective matrix (OMAX) method

\begin{tabular}{|c|c|c|c|c|}
\hline $\begin{array}{c}\text { Rasio } \\
\text { Efektifitas Hasil } \\
\text { Produksi }\end{array}$ & $\begin{array}{c}\text { Rasio Jam } \\
\text { Kerja Efektif }\end{array}$ & $\begin{array}{l}\text { Rasio Jumlah } \\
\text { Produk Cacat }\end{array}$ & $\begin{array}{c}\text { Rasio } \\
\text { Downtime } \\
\text { mesin }\end{array}$ & $\begin{array}{l}\text { Productivity } \\
\text { Criteria }\end{array}$ \\
\hline 95 & 95 & 0,1 & 8 & Performance \\
\hline 100 & 100 & 0,89 & 7,28 & 10 \\
\hline 99,75 & 99,03 & 0,90 & 7,66 & 9 \\
\hline 99,51 & 98,06 & 0,903 & 8,06 & 8 \\
\hline 99,27 & 97,09 & 0,904 & 8,44 & 7 \\
\hline 99,02 & 96,12 & 0,906 & 8,83 & 6 \\
\hline 98,78 & 95,15 & 0,907 & 9,22 & 5 \\
\hline 98,54 & 94,18 & 0,908 & 9,61 & 4 \\
\hline 98,30 & 93,21 & 0,1 & 10 & 3 \\
\hline 94,62 & 83,35 & 1,15 & 19,97 & 2 \\
\hline 89,19 & 82,61 & 1,24 & 21,04 & 1 \\
\hline 85,09 & 75,71 & 1,57 & 32,08 & 0 \\
\hline 2 & 5 & 3 & 8 & Score \\
\hline 33,33 & 16,67 & 33,33 & 16,67 & Weigt \\
\hline \multirow[t]{2}{*}{66,66} & 83,35 & 99,99 & 133,36 & Value \\
\hline & & & $\begin{array}{l}\text { Previous } \\
300\end{array}$ & $\begin{array}{l}\text { Index } \\
27,79 \%\end{array}$ \\
\hline
\end{tabular}

Tabel 3.4. Objective Matrix pada periode 11

Pada periode 11 (dibandingkan dengan periode 10) terjadi kenaikan produktivitas, hal itu dapat terlihat karena nilai IP (indeks produktivitas) yang bernilai positif (+) yaitu sebesar 12,49 dan terjadi kenaikan dinilai perhitungan pada saat pengukuran (current) dari 228,54 menjadi 257,09. Peningkatan ini disebabkan karena terjadinya peningkatan nilai dari seluruh kriteria.

\section{Analisa Pengukuran Produktifitas OMAX}

Analisa pengukuran produkifitas berdasarkan kriteria dilakukan untuk mengetahui kriteria yang berpengaruh dan harus ditingkatkan. Dari Tabel 5 diperoleh score dari masing-masing kriteria produktifitas.

\begin{tabular}{ccccc}
\hline Periode & Score Kriteria 1 & Score Kriteria 2 & Score Kriteria 3 & Score Kriteria 4 \\
\hline 1 & 2 & 3 & 0 & 9 \\
2 & 2 & 3 & 3 & 3 \\
3 & 2 & 3 & 1 & 10 \\
4 & 5 & 2 & 1 & 2 \\
5 & 1 & 3 & 2 & 3 \\
6 & 5 & 1 & 10 & 1 \\
7 & 2 & 2 & 10 & 2 \\
8 & 0 & 2 & 10 & 2 \\
9 & 10 & 0 & 1 & 0 \\
10 & 2 & 2 & 9 & 2 \\
\hline
\end{tabular}

Tabel 3.5. Score kriteria produktifitas

Dari hasil score masing-masing kriteria produktifitas menunjukkan bahwa pada score kriteria pertama dan kedua sangat perlu ditingkatkan karena nilai score yang dihasilkan didominasi produktivitas buruk cukup banyak. Pada kriteria ketiga menunjukkan score yang cenderung baik bahkan ada yang berada pada tingkat baik sekali. Untuk Kriteria 
Katrin, et al Productivity analysis of filling machine with the objective matrix (OMAX) method

keempat juga perlu ditingkatkan meskipun sudah cukup baik agar produktivitas perusahaan semakin meningkat. Sedangkan untuk kriteria keempat meskipun sudah cukup baik agar produktivitas perusahaan semakin meningkat.

\section{Pembuatan Fish Bone Diagram}

Dengan menggunakan diagram tulang ikan, faktor - faktor penyebab produktivitas yang dihasilkan menurun secara garis besar dikelompokka ke dalam berbagai kategori Manusia (Man), Material, Mesin (Machine), Lingkungan (Environment), Metode (Methode) (Kholil \& Yogaswara, 2006).

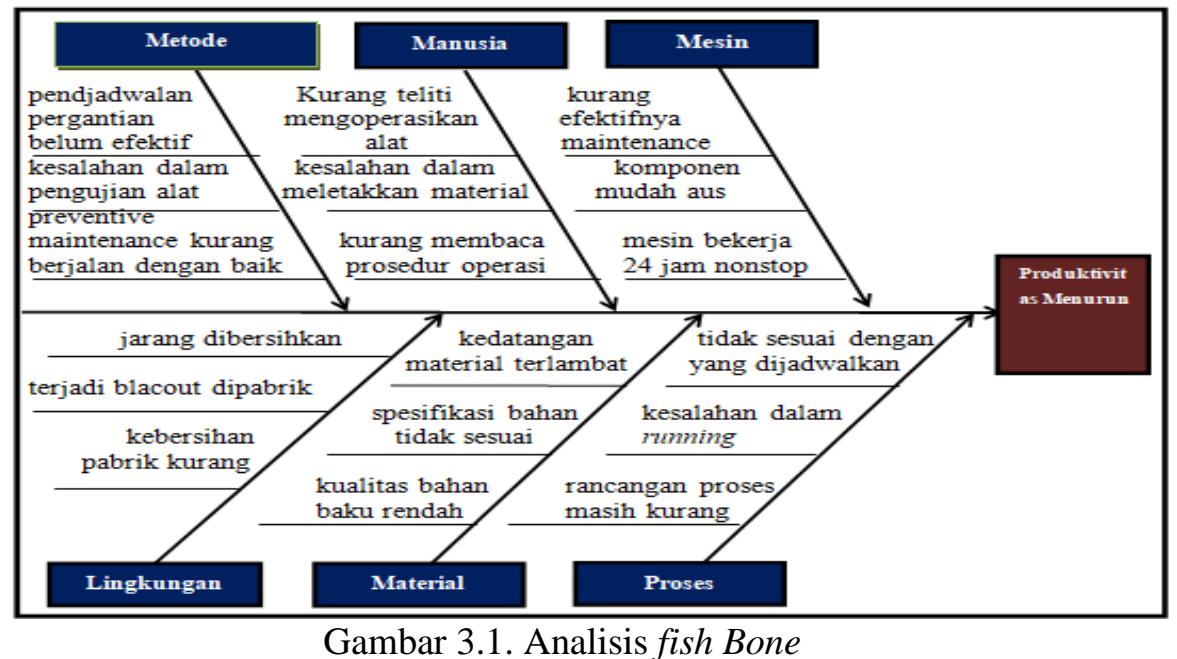

Dari hasil analisa produktivitas diketahui faktor-faktor yang mempengaruhi penurunan produktivitas ditunjukkan pada Gambar 1 di bawah ini. Berdasarkan faktor-faktor yang mempengaruhi penurunan produktivitas yang ditunjukkan pada Gambar 1, maka dilakukan perancangan solusi seperti yang ditunjukkan pada Tabel 3.6.

\begin{tabular}{|c|c|c|c|}
\hline \multicolumn{4}{|c|}{ Produktivitas Menurun } \\
\hline No & Faktor & Analisis & Tindakan \\
\hline 1 & Manusia & $\begin{array}{lr}\text { Kurangnya } & \text { ketelitian } \\
\text { operator } & \text { dalam } \\
\text { melaksanakan } & \text { prosedur } \\
\text { kerja } & \text { yang } \\
\text { mengakibatkan } & \\
\text { breakdown } & \end{array}$ & $\begin{array}{l}\text { Memberikan pelatihan dan training } \\
\text { kembali tentang cara dan prosedur kerja } \\
\text { yang baik dan benar, selalu melakukan } \\
\text { briefing untuk mengetahui kondisi kerja } \\
\text { dilapangan setiap harinya. }\end{array}$ \\
\hline 2 & Mesin & $\begin{array}{l}\text { Mesin aus, pemberian } \\
\text { pelumas yang jarang, } \\
\text { perawatan yang tidak } \\
\text { rutin. }\end{array}$ & $\begin{array}{l}\text { Diberikan jadwal khusus untuk kegiatan } \\
\text { maintenance yang rutin, pemberian } \\
\text { pelumas pada alat sebelum digunakan, } \\
\text { selalu melakukan pengecekan sebelum } \\
\text { alat mulai running. }\end{array}$ \\
\hline 3 & Material & $\begin{array}{l}\text { Kedatangan bahan baku } \\
\text { yang terlambat, keadaan } \\
\text { bahan baku yang tidak } \\
\text { sesuai dengan sesifikasi. }\end{array}$ & $\begin{array}{l}\text { Melakukan pengecekan setiap saat } \\
\text { untuk mencegah kehabisan bahan baku } \\
\text { saat proses produksi, melakukan analisa } \\
\text { laboratorium terlebih dahulu sebelum } \\
\text { digunakan. }\end{array}$ \\
\hline 4 & Metode & $\begin{array}{lrr}\text { Prosedur yang } & \text { tidak } \\
\text { sesuai dengan } & \text { SOP } \\
\text { pabrik. } & & \\
& \end{array}$ & $\begin{array}{l}\text { Memasang prosedur kerja dan cara } \\
\text { pemakaian pada masing - masing alat. }\end{array}$ \\
\hline
\end{tabular}


Katrin, et al Productivity analysis of filling machine with the objective matrix (OMAX) method

5 Lingkungan Alat jarang dibersihkan, sering terjadi mati lampu.

$6 \quad$ Proses
Kurang berjalannya proses yang sesuai dengan dijadwalkan.
Dalam satu minggu diberikan satu hari khusus untuk sanitasi dan juga mengontrol mati lampu dengan adanya jenset.

Melakukan kontrol terhadap mesin tersebut, melakukan pencegahan dengan mengatasi keadaan hal - hal kecil seperti pemeriksaan setiap bagian alat.

\section{KESIMPULAN}

Tabel 3.6. Rancangan Solusi

Dengan Metode OMAX dapat diketahui pada periode 11 (dibandingkan dengan periode 10) terjadi kenaikan produktivitas, hal itu dapat terlihat karena nilai IP (indeks produktivitas) yang bernilai positif $(+)$ yaitu sebesar 27,79 dan terjadi kenaikan dinilai perhitungan pada saat pengukuran (current) dari 383,36 menjadi 300. Peningkatan ini disebabkan karena terjadinya peningkatan nilai dari seluruh kriteria.

Dari hasil analisa produktivitas berdasarkan kriteria, maka kriteria yang paling perlu untuk ditingkatkan adalah kriteria pertama dan kedua, yaitu Rasio Efektifitas hasil produksi dan Rasio Jam kerja efektif. Hal ini dapat ditingkatkan dengan cara miningkatkan jumlah produksi, mengurangi produk cacat dengan pengawasan yang baik, memanfaatkan jam kerja secara optimal dan melakukan perawatan intensif terhadap mesin.

\section{DAFTAR PUSTAKA}

Agustina, F., \& Riana, N.A. (2011). Analisis Produktivitas dengan Metode Objective Matrix (OMAX) di PT. X. Jurnal Teknik dan Manajemen Industri, 6, 150-158.

Avianda, D., Yuniati, Y., \& Yuniar. (2014). Strategi Peningkatan Produktivitas di Lantai Produksi Menggunakan Metode Objective Matrix (OMAX). Jurnal Teknik Industri Itenas, 1, 202203.

Faridz, R., Burhan, Wijayantie, A.E. (2011). Pengukuran dan Analisis Produktivitas Produksi dengan Metode Objective Matrix (OMAX) di PG. Krebet Baru Malang. Jurnal Teknologi Industri Pertanian, 5, 80-87.

Kholil, M., \& Yogaswara, Y. (2006). Analisa Pengukuran Produktivitas Model Objective Matrix pada Departemen Produksi Pabrik Furniture Garden PT. QUARTINDO SEJATI FURNITAMA. Jurusan Teknik Indistri, Universitas Mercu Buana Jakarta.

Nurdin, R., \& Zabidi, Y. (2008). Pengukuran dan Analisis Produktivitas Lini Produksi Perusahaan Dengan Menggunakan Metode Objective Matrix. Jurusan Teknik Industri, Sekolah Tinggi Teknologi Adi Sutjipto (STTA).

Pangaula, S. F., Saroyo, P., \& Widodo, K.H. (2015). Pengukuran Produktivitas di PT. Madusari Nusaperdana Boyolali. Universitas Gadjah Mada.

Rahmi, G.A., Bakar, A., \& Desrianty, A. (2013). Analisis Peningkatan Produktivitas Di Lantai Produksi dengan Menggunakan Metode Objective Matrix (OMAX). Jurnal Teknik Industri Itenas, 1, 33-42.

Riggs, J. L. (1987), Production System Planning, Analysis and Control, John Wiley \& Sons Inc., Singapore.

Summanth. (1984). Productivity Engineering and Management. Mc Grow Hill Book. New York.

Zanuar, R. A., \& Suharno. (2014). Pengukuran Produktivitas pada Lini Produksi di PTPN IX (PERSERO) Kopi Banaran Menggunakan Metode Objective Matrix (OMAX). Universitas Gadjah Mada. 